\title{
Acute on chronic hepatic failure due to hepatitis B infection: A case report
}

\author{
Busayo Adetunji ${ }^{1}$, Kehinde Alare ${ }^{1}$, Samson Afolabi ${ }^{1}$, Akinbode Olajire ${ }^{2}$, Oyaronbi Adegboye ${ }^{3}$ \\ ${ }^{1}$ Department of Medicine, Ladoke Akintola University of Technology, Ogbomosho, Oyo State, Nigeria. ${ }^{2}$ Nigerian Navy \\ Reference Hospital, Ojo, Nigeria. ${ }^{3}$ Department of Biochemistry, Ladoke Akintola University of Technology, Ogbomosho Oyo \\ State, Nigeria.
}

\begin{abstract}
Background: Acute on chronic liver failure, also known as acutely decompensated cirrhosis, is a clinical condition characterized by sudden hepatic decompensation in patients with pre-existing chronic liver dysfunction, as well as extrahepatic organ defects and increase mortality in some patients. The prevalence of acute on chronic liver failure and the associated mortality rate is high in both developed and developing countries. We report the case of a 19 year old male patient with a three year history of hepatitis B virus infection who presented to the hospital with jaundice and progressive generalized body swelling. Six days later, the patient developed hematemesis, ascites, melena and progressive body weakness. We present a case report and a review of literature on acute on chronic hepatic failure with a focus on the role of chronic hepatitis B infection.
\end{abstract}

\section{Introduction}

Acute on chronic liver failure or acutely decompensated cirrhosis is a clinical syndrome of sudden hepatic decompensation (ascites, encephalopathy, gastrointestinal haemorrhage, bacterial infection) seen in patients with preexisting chronic liver pathology and in some patients associated with extrahepatic organ failures and increased mortality ${ }^{1-5}$. The prevalence of acute on chronic liver failure and the associated mortality rate is high in both developed and developing countries ${ }^{6-8}$.

In this article, we report acute-on-chronic liver failure in a patient with Hepatitis B viral infection and we want to put limitations in the diagnosis of acute-on-chronic liver failure, as well as its management, in context. In addition, we briefly review the subject with emphasis on the role of hepatitis $\mathrm{B}$ virus infection.

\section{Case Report}

A 19 year old male patient presented to our emergency department after a week of progressive body swelling and

\footnotetext{
Keywords: Hepatitis B Infection, Acute on chronic liver failure, culture positive spontaneous bacterial, Hepatic failure, Liver disease

Received: 1-5-2021; Accepted: 18-6-2021

* Corresponding author. Email: henrybusayo04@gmail.com
}

jaundice. He was well until a week prior to his presentation when he noticed abdominal swelling progressively spread to the legs. There is no history of reduced urine output. At about the same time, he noticed jaundice which is reported to be progressive with associated dark coloured urine. There is also a history of generalized body weakness. Patient was diagnosed as chronic hepatitis B virus infection three years prior to presentation. Interaction with family revealed no history of alcoholism or family history of Wilsons disease. He denied history of hematemesis and melena. Physical examination shows: Blood pressure 128/68mmHg, pulse rate 102 per minute, respiratory rate 22 cycles per minute, jaundice, abdomen was distended with the liver tipped below the right coastal margin with the spleen palpable enlarged and ascites was demonstrable by shifting dullness, digital rectal examination was unrevealing, no encephalopathy. Laboratory investigations reveals total bilirubin 314 umol/l (up to 20 umol/l), conjugated bilirubin 285 (up to $5 \mathrm{umol} / \mathrm{l}$ ), alanine aminotransferase (ALT) 89 U/L (up to 12), aspartate transaminase (AST) $20 \mathrm{U} / \mathrm{L}$ (up to 12), Alkaline phosphatase 38U/L (9-35). Renal function test was non-contributing [fig 1].

Viral profile showed positive hepatitis B surface antigen (HBsAg) and there was normal level of ceruloplasmin and copper. Patient was place on furosemide, spironolactone, lactulose and hepatotonic phospholipids with vitamins, entecavir and discharged after four days on admission. Six days later, he presented with frank hematemesis of two episodes. Examination revealed the following: blood pressure $79 / 43 \mathrm{mmHg}$, pulse rate 108 per min, respiratory rate 22 cycles per min, $\mathrm{SpO} 295 \%$ while breathing ambient air, icteric, pale, bilateral pedal edema. Patient is with signs of grade II hepatic encephalopathy. Abdomen is distended and moves with respiration, liver is tipped and spleen enlarged. Admitting Packed Cell Volume (PCV) 19\%.

Result of the abdominopelvic ultrasound scan revealed a liver of $14.64 \mathrm{~cm}$ in span with smooth outline and homogenous parenchymal echo pattern. Spleen is enlarged $18.11 \mathrm{~cm}$. A repeat hepatitis $\mathrm{B}$ virus screening revealed positive to HBsAg but negative for Anti-HCV Screening. Parent were both negative for HBsAg. Patient was transfused with four pints of blood and managed with rebaprazole, lactulose, maintenance fluid, antibiotics and other supportive therapy were given. 


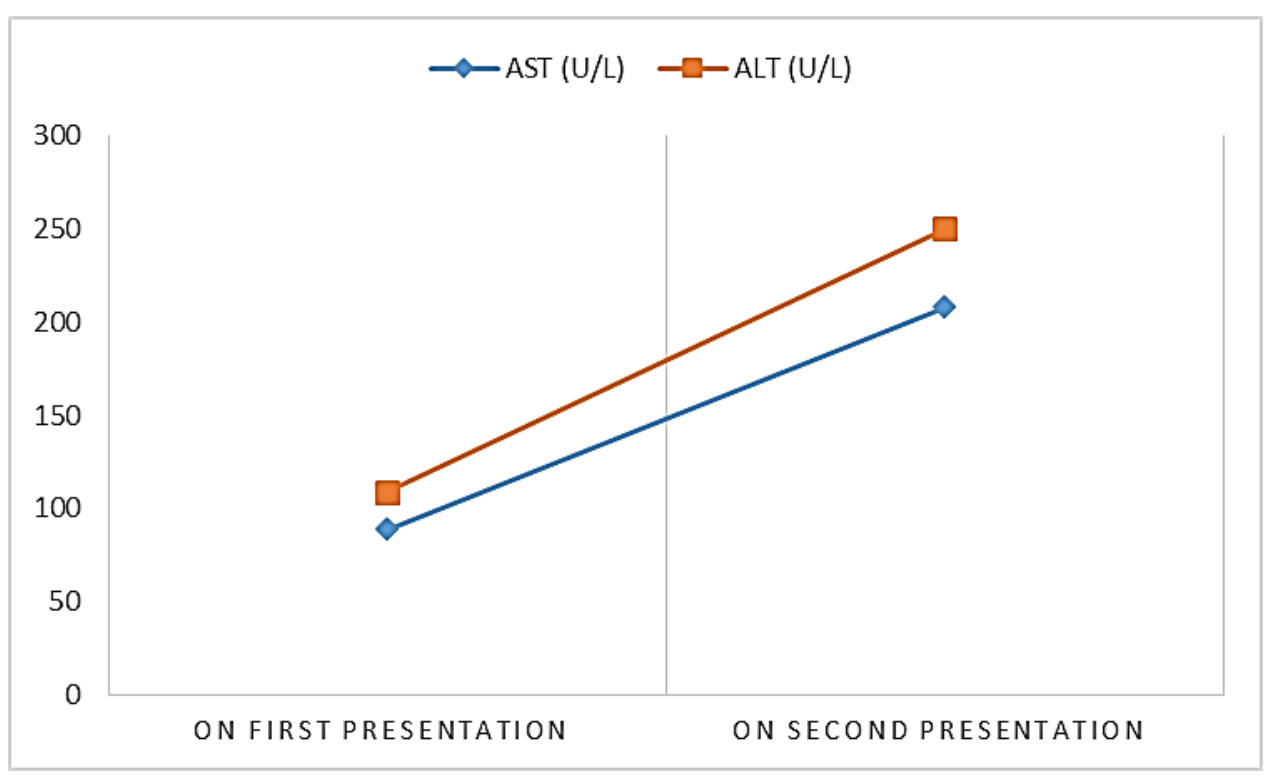

Fig. 1: Relationship between AST and ALT in the patient on first presentation and second presentation.

Table 1. Laboratory data of the case.

\begin{tabular}{lccc}
\hline \multicolumn{1}{c}{ Variable } & Reference range & On First Presentation & $\begin{array}{c}\text { On Second } \\
\text { Presentation }\end{array}$ \\
\hline Haematocrit (\%) & $30-46$ & 28 & 19 \\
\hline Total Bilirubin (umol/L) & Up to 20 & 315 & 612 \\
\hline $\begin{array}{l}\text { Conjugated Bilirubin } \\
\text { (umol/L) }\end{array}$ & Up to 5 & 285 & 489 \\
\hline Protein (g/l) & $58-80$ & 70 & 68 \\
\hline Albumin (g/l) & $35-50$ & 25 & 20 \\
\hline AST (U/L) & Up to 12 & 89 & 208 \\
\hline $\begin{array}{l}\text { ALT (U/L) } \\
\text { Alkaline phosphatase } \\
\text { (U/L) }\end{array}$ & Up to 12 & 20 & 42 \\
\hline
\end{tabular}




\section{Original Article}

\section{Discussion}

Over the years, there has been a disparity between the west and east in the definition of Acute on Chronic Liver Failure but, they mostly address the role exacerbation of a chronic liver disease by precipitating factors. The AsiaPacific Association for the Study of Liver (APASL) defined acute on chronic liver failure as acute hepatic insult manifesting as jaundice and coagulopathy, complicated within 4 weeks by ascites and/or encephalopathy in a patient with previously diagnosed or undiagnosed chronic liver disease ${ }^{4}$. The definition by the European Association for the Study of the Liver-Chronic Liver Failure (EASL-CLIF) Consortium and North American Consortium for the Study of End-Stage Liver Disease, includes extrahepatic organ failures and the role of extrahepatic precipitating events ${ }^{9}$.

\section{Epidemiology}

Epidemiological data on acute on chronic liver failure is limited. Using the Asia-Pacific Association for the Study of Liver (APASL), the incidence of acute on chronic liver failure was 5.7 in 1000 persons per year and 20.1 in 1000 persons per year using the European criteria as reported in literature ${ }^{10}$.

EASL-CLIF pegs mortality rate in patients with acute on chronic liver failure between 30 to $53 \%$. The North American Consortium for the Study of End-Stage Liver Disease reported mortality of $27.8 \%, 49 \%, 64 \%$ and $77 \%$ in stage $1,2,3$, and 4 end organ failures respectively ${ }^{3,11}$. Data on the incidence of acute on chronic liver failure in Nigeria is unknown but the prevalence of hepatitis B infection is a common precipitating factor in Nigeria and Asia ${ }^{12-14}$.

\section{Pathophysiology and clinical presentation}

The pathophysiology of acute-on-chronic liver failure is still largely unknown. However severe systemic inflammation with elevated levels of cytokines IL-6, IL-8, IL-10, IL-12 and interferon-gamma, leukocytes and chemokines has been stated to play a role in its development 15,16. Normally, an acute precipitating event causes an increase inflammatory markers in the blood and resulting in further damage of the liver. Studies have found a direct proportionality between the systemic inflammation and the severity of acute-on-chronic liver failure. Patients with high intensity of systemic inflammation have higher number of organ failures and higher mortality ${ }^{15}$. The clinical picture is that of a known patient with chronic liver disease presenting with features of extra-hepatic organ failure including high output cardiac failure, gastrointestinal bleeding, hepatic encephalopathy, cerebral oedema, acute kidney injury and acute respiratory failure.

\section{Preciptating factor}

The factors leading to an acute decompensation of liver function in a background chronic liver disease include hepatitis B virus reactivation, acute viral hepatitis (A, C, D, $\mathrm{E}$ ), alcoholic hepatitis, variceal bleeding, bacterial or fungal infection, sepsis, drug induced liver failure, hypoxic injury, surgical trauma, cytotoxic therapy and herbal drugs. However, $43.6 \%$ had an unidentifiable trigger in some study, while another study revealed $20.4 \%$ with unknown triggers $10,17-23$.

\section{Treatment}

The principle of treatment of acute on chronic liver failure including, early identification and treatment of precipitating factor, prevention and early treatment of organ failure. Patients should be admitted to the ICU and treatment is multidisciplinary with a liver specialist overseeing the team.

\section{Prevention of Precipitating Factors}

\section{Hepatitis B Virus Reactivation}

Literature has shown improved biochemical and virologic outcome in patients treated with long term lamivudine ${ }^{24-26}$. Alternative treatments of choice include adefovir, alafenamide, tenofovir, or entecavir ${ }^{4,26}$.

\section{Hepatitis A, C, D, E}

The goal is to achieve constant viral suppression ${ }^{11}$

\section{Variceal Bleeding}

Treatment for variceal bleeding includes the use of vasoconstrictors and endoscopic therapy ${ }^{27,28}$. Prophylaxis proton pump inhibitors should also be started.

\section{Bacterial Infection}

Treatment for bacterial infection should be commenced swiftly. Literature reports delayed diagnosis and treatment of infections in patients with ACLF results in a poor prognosis ${ }^{29}$. Prophylactic antibiotic therapy is suitable to prevent bacterial infections in high-risk patients ${ }^{29,30}$.

\section{Supportive Management Liver Support Systems}

Extracorporal liver support systems such as albumin dialysis and/or plasma exchange have been proposed as new therapeutic options for patients with acute on chronic liver failure $^{31,32}$.

\section{Hepatic Encephalopathy}

Lactulose a non-absorbable sugar reduces gut $\mathrm{pH}$ and treats constipation ${ }^{33}$. Airway protection should also be maintained and in severe cases, enemas be administered.

\section{Transplantation.}

When acute liver failure can't be reversed, the only treatment may be a liver transplant ${ }^{34}$. However, transplantation in patients with ACLF, mostly those with serious stages, is complex and controversial, especially these patients presented with many contraindications. In this setting, and because of the high short-term mortality rate, the LT to these patients is small ${ }^{35}$.

\section{Conclusion}

This article describes the case of 19 year old patient who developed a clinical picture of acute on chronic liver diseases. He was diagnosed of hepatitis B virus infection three year prior to his presentation. With the high incidence and prevalence of Hepatitis B Virus Infection in developing 
countries, we recommend an increase public health education and vaccination against hepatitis B infection. The availability of resources plays a role in the delayed diagnosis of acute on chronic liver failure in our facility.

\section{References}

1. Moore, K. P., Wong, F., Gines, P., et al. (2003). The management of ascites in cirrhosis: report on the consensus conference of the International Ascites Club. Hepatology, 38(1), 258-266.

2. Jalan, R., and Williams, R. (2002). Acute-on-chronic liver failure: pathophysiological basis of therapeutic options. Blood purification, 20(3), 252-261.

3. Olson, J. C., Wendon, J. A., Kramer, D. J., et al. (2011). Intensive care of the patient with cirrhosis. Hepatology, 54(5), 1864-1872.

4. Sarin, S. K., Kumar, A., Almeida, J. A., et al. (2009). Acute-on-chronic liver failure: consensus recommendations of the Asian Pacific Association for the study of the liver (APASL). Hepatology international, 3(1), 269-282.

5. Hernaez, R., Kramer, J. R., Liu, Y., et al. (2019). Prevalence and short-term mortality of acute-onchronic liver failure: a national cohort study from the USA. Journal of hepatology, 70(4), 639-647.

6. Li, H., Chen, L. Y., Zhang, N. N., et al. (2016). Characteristics, diagnosis and prognosis of acute-onchronic liver failure in cirrhosis associated to hepatitis B. Scientific reports, 6(1), 1-14.

7. Bajaj JS, O'Leary JG, Reddy KR, Wong F, Biggins SW, Patton H, Fallon MB, Garcia-Tsao G, Maliakkal B, Malik R, Subramanian RM, Thacker LR, Kamath PS; North American Consortium For The Study Of End-Stage Liver Disease (NACSELD). Survival in infection-related acute-on-chronic liver failure is defined by extrahepatic organ failures. Hepatology. 2014 Jul;60(1):250-6.

8. Amarapurkar, D., Dharod, M. V., Chandnani, M., et al. (2015). Acute-on-chronic liver failure: a prospective study to determine the clinical profile, outcome, and factors predicting mortality. Indian Journal of Gastroenterology, 34(3), 216-224.

9. Moreau, R., Jalan, R., Gines, P., et al. (2013). Acuteon-chronic liver failure is a distinct syndrome that develops in patients with acute decompensation of cirrhosis. Gastroenterology, 144(7), 1426-1437.

10. Mahmud, N., Kaplan, D. E., Taddei, T. H., et al. (2019). Incidence and mortality of acute-on-chronic liver failure using two definitions in patients with compensated cirrhosis. Hepatology, 69(5), 2150-2163.

11. Shah, N.J., Mousa, O.Y., Syed, K., et al (2021). Acute On Chronic Liver Failure. Treasure Island (FL): StatPearls Publishing, 29763077.

12. Olaniyan, A., Oke, G., Folaranmi, P., \& Adetunji, B. (2020). Exploring the Knowledge, Attitude and Practice Regarding Hepatitis B Infection among Ogbomosho LGA Dwellers: A Cross-Sectional Study. J Hepat Res, 5(1), 1039.
13. Olayinka, A. T., Oyemakinde, A., Balogun, M. S., et al. (2016). Seroprevalence of hepatitis B infection in Nigeria: A national survey. The American journal of tropical medicine and hygiene, 95(4), 902.

14. Clària, J., Stauber, R. E., Coenraad, M. J., et al. (2016). Systemic inflammation in decompensated cirrhosis: characterization and role in acute-on-chronic liver failure. Hepatology, 64(4), 1249-1264.

15. Wasmuth, H. E., Kunz, D., Yagmur, E., et al. (2005). Patients with acute on chronic liver failure display 'sepsis-like'immune paralysis. Journal of hepatology, 42(2), 195-201.

16. Shi, Y., Yang, Y., Hu, Y., et al. (2015). Acute-onchronic liver failure precipitated by hepatic injury is distinct from that precipitated by extrahepatic insults. Hepatology, 62(1), 232-242.

17. Sargenti, K., Prytz, H., Nilsson, E., et al. (2015). Predictors of mortality among patients with compensated and decompensated liver cirrhosis: the role of bacterial infections and infection-related acuteon-chronic liver failure. Scandinavian journal of gastroenterology, 50(7), 875-883.

18. Kumar, M., Sharma, B. C., and Sarin, S. K. (2008). Hepatitis E virus as an etiology of acute exacerbation of previously unrecognized asymptomatic patients with hepatitis B virus-related chronic liver disease. Journal of gastroenterology and hepatology, 23(6), 883-887.

19. Lok, A. S., and Lai, C. L. (1990). Acute exacerbations in Chinese patients with chronic hepatitis B virus (HBV) infection: incidence, predisposing factors and etiology. Journal of hepatology, 10(1), 29-34.

20. Sánchez-Tapias, J. M., Costa, J., Mas, A., Bruguera, M., et al. (2002). Influence of hepatitis B virus genotype on the long-term outcome of chronic hepatitis B in western patients. Gastroenterology, 123(6), 18481856.

21. Acharya, S. K., Sharma, P. K., Singh, R., et al. (2007). Hepatitis E virus (HEV) infection in patients with cirrhosis is associated with rapid decompensation and death. Journal of hepatology, 46(3), 387-394.

22. Kumar, A., Das, K., Sharma, P., et al. (2009). Hemodynamic studies in acute-on-chronic liver failure. Digestive diseases and sciences, 54(4), 869878.

23. Zoulim, F., and Perrillo, R. (2008). Hepatitis B: reflections on the current approach to antiviral therapy. Journal of hepatology, 48, S2-S19.

24. Inoue, T., Fuke, H., Yamamoto, N., et al. (2007). Lamivudine for treatment of spontaneous exacerbation and reactivation after immunosuppressive therapy in patients with hepatitis B virus infection. Hepatogastroenterology, 54(75), 889-891.

25. Liaw, Y. F., Sung, J. J., Chow, W. C., et al. (2004). Lamivudine for patients with chronic hepatitis B and advanced liver disease. New England Journal of Medicine, 351(15), 1521-1531.

26. D'Amico, G., Pagliaro, L., and Bosch, J. (1999). Pharmacological treatment of portal hypertension: an evidence-based approach. In Seminars in liver 
disease (Vol. 19, No. 04, pp. 475-505). (C) 1999 by Thieme Medical Publishers, Inc..

27. Kim, Y. D. (2014). Management of acute variceal bleeding. Clinical endoscopy, 47(4), 308.

28. Engelmann, C., and Berg, T. (2018). Management of infectious complications associated with acute-onchronic liver failure. Visceral medicine, 34(4), 261268.

29. Aparicio, J. R., Such, J., Pascual, S., et al. (1999). Development of quinolone-resistant strains of Escherichia coli in stools of patients with cirrhosis undergoing norfloxacin prophylaxis: clinical consequences. Journal of hepatology, 31(2), 277-283.

30. Bañares, R., Nevens, F., Larsen, F. S., et al. (2013). Extracorporeal albumin dialysis with the molecular adsorbent recirculating system in acute-on-chronic liver failure: the RELIEF trial. Hepatology, 57(3), 1153-1162.

31. Kribben, A., Gerken, G., Haag, S., et al. (2012). Effects of fractionated plasma separation and adsorption on survival in patients with acute-on-chronic liver failure. Gastroenterology, 142(4), 782-789.

32. Hudson, M., and Schuchmann, M. (2019). Long-term management of hepatic encephalopathy with lactulose and/or rifaximin: a review of the evidence. European journal of gastroenterology \& hepatology, 31(4), 434.

33. Nooshkam, M., Babazadeh, A., and Jooyandeh, H. (2018). Lactulose: Properties, techno-functional food applications, and food grade delivery system. Trends in Food Science \& Technology, 80, 23-34.

34. Blackmore, L., and Bernal, W. (2015). Acute liver failure. Clinical medicine, 15(5), 468.

35. Putignano, A., and Gustot, T. (2017). New concepts in acute-on-chronic liver failure: implications for liver transplantation. Liver transplantation, 23(2), 234-243. 